\title{
Investigando as pesquisas sobre analogias: o que mostram os anais dos encontros de ensino de ciências? ${ }^{1}$
}

\author{
Francisco Alves Santos* \\ Faculdade de Educação de Itapipoca - FACEDI/UECE \\ Isabel Cristina Higino Santana** \\ Faculdade de Educação de Itapipoca - FACEDI/UECE
}

Resumo A linguagem analógica enquanto instrumento de mediação conceitual em ciências vem sendo explorada por muitos, e consequentemente, alvo de diferentes estudos na tentativa de compreender sua funcionalidade. Assim, a pesquisa buscou quantificar as publicações referentes ao uso de analogias em contextos didáticos mapeando as linhas investigativas nas pesquisas educacionais. Para atingir tais fins, realizou-se uma consulta de Anais dos Encontros Nacionais de Ensino de Biologia - (ENEBio); Encontro Nacional de Didática e Práticas de Ensino - (ENDIPE) e Encontros Nacionais de Pesquisa em Ensino em Ciências - (ENPEC) no período de 2000-2016. O material identificado foi lido na íntegra e posteriormente analisados. Como resultado, foram identificadas 92 comunicações científicas sobre o tema, distribuídas em 6 linhas de pesquisas: utilização e exploração didática de analogias, analogias em manuais escolares; analogias na prática dos professores de ciências; analogias e as concepções de professores sobre o seu papel no processo de ensino -aprendizagem; analogias e os estudos de revisão; analogias e ensino. As duas primeiras linhas apresentaram o maior número de pesquisas. Concluiu-se que, embora a exploração de analogias na perspectiva do ensino e da aprendizagem em Ciência mantenha os padrões apresentados em estudos anteriores, percebe-se um crescimento do escopo teórico acerca do tema, em âmbito nacional nos últimos anos; permitindo delinear novas formas de trabalhar o tema nos mais variados campos do conhecimento científico, requerendo assim, ações que propiciem a discussão e reconhecimento deste recurso com os fenômenos do ensino e da aprendizagem na promoção do ensino de Ciências.

PALAVRAS-CHAVE: Linguagem analógica; Ensino de ciências; Estado da arte. 


\section{Investigating research on analogies: what do the annals of science education meetings show?}

Abstract Analogical language has been explored by many as an instrument of conceptual mediation in sciences and has consequently been the target of different studies in an attempt to understand its functionality. Thus, this research aimed to quantify publications on the use of analogies in didactic contexts by mapping research lines in educational research. For this purpose, the Annals of the National Meetings of Biology Teaching (ENEBio); National Meeting of Didactics and Teaching Practices (ENDIPE); and National Meetings of Research and Teaching of Sciences ENPEC during the period from 2000 to 2016 were consulted. The material was read in full and subsequently analyzed. As a result, 92 scientific communications on the topic were identified, distributed along six lines of research: the use and didactic exploration of analogies; analogies in school textbooks; analogies in the practice of Science teachers; analogies and teachers' views of their roles in the teaching-learning process; analogies and review studies; analogies and teaching. The first two lines yielded the highest number of research studies. It was concluded that, while the exploration of analogies from a Science teaching-learning perspective demonstrates the standards presented in previous studies, there has been an increase in the theoretical scope of the theme at the national level in recent years. This helps to outline new ways of working with the theme in various fields of scientific knowledge, which require actions to facilitate discussion and recognition of this resource, in terms of teaching and learning as it relates to the promotion of Science education.

KEYWORDS: Analogical language; Science teaching; State of the art.

\section{Introdução}

"Conhecer é tarefa de sujeitos, não de objetos. E é como sujeito e somente enquanto sujeito, que o homem pode realmente conhecer. (PAULO FREIRE, 1997, p.15).”

O processo de ensino representa um contínuo caminhar, pelo qual os sujeitos partilham suas experiências em meio à dialogicidade que é estabelecida entre professores e alunos. Através do diálogo, os sujeitos constroem vínculos nos quais o conhecimento é partilhado. Partindo desta compreensão, professores e alunos tornamse sujeitos ativos no processo de ensino e aprendizagem, embora, a comunicação entre eles necessite de um código que permita aos interlocutores reconhecer-se neste diálogo.

As atividades de Ensino de Ciências, em especial as Ciências da Natureza, apresentam um conjunto de nomenclaturas específicas que é própria de uma comunidade, a científica. Dialogar com os conceitos, leis e teorias que perfazem o ensino dessas Ciências representa a inserção e a compreensão em um contexto específico, que cada dia mais se embrenha no cotidiano de nossos alunos. 
No entanto, inserir-se nessa cultura, implica na interação com conceitos abstratos que não encontram na maioria das vezes, correspondências com as atividades partilhadas no contexto escolar. O distanciamento entre o discurso do professor ao apresentar conceitos científicos em sala de aula, e a carência de recursos materiais que possam subsidiar o trabalho com determinados temas, acabam por configurar-se como um agravante na relação já desgastada com as disciplinas de abordagem científica e muitas vezes abstrata, como a biológica, por exemplo.

Estas inquietações nasceram de experiências durante a formação inicial enquanto licenciando em Ciências Biológicas, através de ações proporcionadas pelo projeto de iniciação científica da Universidade Estadual do Ceará/UECE,- contemplado com uma bolsa de Iniciação Científica e Tecnológica (ICT) pela Fundação Cearense de Apoio ao Desenvolvimento Científico e Tecnológico (FUNCAP) - denominado "O conceito científico nas ciências: o uso de analogias como instrumento didático dessa construção" no qual foi oportunizado conhecer e identificar a presença e uso deste instrumento em contexto de ensino e aprendizagem.

As vivências do tipo, encontros, oficinas e minicursos - promovidos pelo grupo de pesquisadores envolvidos, - tornou possível a discussão entre os mesmos e professores sobre a importância deste instrumento didático no contexto do ensino e da aprendizagem. $\mathrm{Na}$ organização desses momentos, as consultas a periódicos, Anais de congressos e acervos online das bibliotecas de algumas universidades brasileiras foram atividades constantes durante todo o percurso, permitindo dimensionar os esforços de estudiosos na promoção do entendimento da analogia enquanto instrumento pedagógico.

Com esse estudo buscamos responder o seguinte questionamento: Quais perspectivas investigativas têm sido privilegiadas nas pesquisas que abordam analogia como instrumento didático, publicadas em encontros nacionais de Ensino de Ciências?

É sabido inicialmente que um número expressivo de estudos brasileiros no cenário educacional tem destacado o papel das analogias como instrumento facilitador do processo de construção conceitual (MOZZER; JUSTI, 2015). Tal concepção está associada ao fato de que esta ferramenta pedagógica está inserida no campo do pensamento e da linguagem, representando uma possibilidade de aproximação entre temáticas científicas e situações do dia a dia.

Um conjunto de investigações tem sido desenvolvido buscando compreender o papel das analogias enquanto recurso didático que auxiliem professores e alunos no processo de construção de conceitos (SILVA; TERRAZZAN, 2005b; BOZELLI; NARDI, 2009; FERRY; PAULLA, 2015). Diante destas investidas, muitos encaminhamentos já foram propostos no sentido de orientar o trabalho com esta ferramenta de ensino. Porém, esse conjunto de conhecimentos já elaborado está disperso e fragmentado nos Anais de encontros científicos.

Dessa forma, neste trabalho, realizou-se a compilação de pesquisas registradas em Anais de encontros nacionais da área de Ensino de Ciências que foram 
dedicadas a linguagem analógica enquanto instrumento didático para a construção de conceitos científicos. Buscando contemplar essa investida, foram delineados como objetivos i) quantificar as publicações referentes ao uso de analogias em contextos didáticos; ii) mapear as linhas investigativas e privilegiadas nas pesquisas educacionais.

\section{Aspectos da pesquisa em Ensino de Ciências}

A realização de estudos que visam analisar a produção de conhecimento na área educacional apresenta uma longa história. Entretanto, neste trabalho não há a pretensão de reconstituir um percurso histórico da pesquisa em Ensino de Ciências, mas apenas, gerar o entendimento sobre a importância da ação em curso.

Neste sentido, observa-se que trabalhos como de Megid Neto e Pacheco (1998); Teixeira e Megid Neto (2006) têm-se debruçado sobre a análise das produções acadêmicas acerca do ensino de Ciências, em especial ao ensino de Biologia e Física, promovendo uma análise acurada sobre a mesma.

Todavia, as pesquisas científicas voltadas à investigação de temas relacionados à Educação são atividades regularmente existentes no Brasil desde fins da década de 1930. Este movimento está relacionado com a criação do Instituto Nacional de Estudos Pedagógicos (INEP) em 1938, e com a criação do Centro de Pesquisas Educacionais (CBPE), estando suas ações delineadas pela administração do setor público (TEIXEIRA e MEGID NETO, 2006; MEGID NETO e PACHECO, 1998).

Mediante estas ações, alguns teóricos têm salientado a necessidade de pesquisa com o foco na educação, como caminho para a promoção da melhoria na qualidade do ensino. Para Bizzo (2009), as pesquisas educacionais representam elementos fortalecedores da melhoria na qualidade do ensino, por proporcionar direcionamentos e percursos que possibilitam o aperfeiçoamento do processo de ensino-aprendizagem.

Na mesma linha de raciocínio, André (2001, p. 52) observa um acentuado "interesse em rever e analisar criticamente o que vem sendo produzido na área, e, em buscar caminhos para seu contínuo aprimoramento". Tal ação se faz necessária em virtude do número intenso de publicações que são destinadas a agrupar os dados produzidos mediante as investigações desenvolvidas.

Nas pesquisas acerca do ensino de Ciências, algumas áreas têm sido privilegiadas, como a que trata do uso de estratégias de ensino, como possiblidade metodológica. A analogia, enquanto instrumento didático tem chamado à atenção de alguns estudiosos do ensino de Ciências, como Dagher (1995), Duarte (2005) e Mozzer e Justi (2015), Cruz-Hastenreiter (2015) que realizaram trabalhos envolvendo a promoção de agrupamentos de partes da produção nacional e internacional acerca do tema.

Entretanto, nos últimos dezesseis anos, expressivas investigações, foram dedicadas em torno do tema, sendo necessária uma reflexão sobre esta produção. Para Teixeira e Megid Neto (2006), após desenvolverem estudos sobre a produção do conhecimento na área educacional consideram fundamental "analisar (...) o impacto dessas pesquisas, em termos de geração de conhecimentos e constituição de um corpo só- 
lido e abrangente de saberes capazes de impulsionar essa área de pesquisa e a melhoria da qualidade educativa nos mais diversos níveis de ensino (TEIXEIRA e MEGID NETO, 2006, p. 265).” Diante deste entendimento, esta pesquisa buscou a realização de um estudo acerca do estado da arte referente ao uso de analogias como instrumento didático voltado ao Ensino de Ciências.

\section{Caminhos percorridos}

A presente pesquisa caracteriza-se como um estudo descritivo, por enfocar a descrição de características particulares da população ou fenômeno, ou ainda o estabelecimento de relações entre variáveis (GIL, 2002). Insere-se no âmbito da pesquisa qualitativa, cujo objetivo é avaliar aspectos não quantificáveis do fenômeno estudado, proporcionando assim, a possibilidade de inferir novas relações a partir das análises realizadas.

O estudo realizado está inserido no grupo de pesquisas denominadas como estudo bibliográfico ou documental, que segundo Gil (2003), é a forma de trabalho desenvolvida a partir do estudo de materiais já elaborados, como por exemplo, livros e artigos científicos. Para Manzo (1971 p.32, apud LAKATOS e MARCONI, 2003), esta perspectiva de estudo "oferece meios para definir, resolver, não somente problemas já conhecidos, como também explorar novas áreas onde os problemas não se cristalizaram suficientemente".

Deste modo, as pesquisas bibliográficas possibilitam uma guisa de reflexões das questões discutidas dentro da comunidade científica possibilitando a compreensão de forma clara sobre determinados problemas e oportunizando a identificação de causas e fatores que têm influenciado esta produção.

Embora traga novos direcionamentos para a superação do problema em estudo, Lakatos e Marconi (2003) entendem que esta forma de estudo não se reduz à mera repetição dos achados já realizados sobre determinado tema, uma vez que permiti reexaminar a partir de uma nova perspectiva, estes dados, levando assim, à elaboração de novas conclusões.

Partindo das considerações já realizadas a respeito das pesquisas de cunho bibliográfico, a pesquisa realizada é denominada como "estado da arte" ou "estado do conhecimento". Esta forma de estudo tem buscado compreender e discutir a produção bibliográfica produzida em um determinado período de tempo. Para Ferreira (2002), este tipo de estudo objetiva:

[...] mapear e discutir uma certa produção acadêmica em diferentes campos do conhecimento, tentando responder que aspectos e dimensões vêm sendo destacados e privilegiados em diferentes épocas e lugares, de que formas e em que condições têm sido produzidas certas dissertações de mestrado, teses de doutorado, publicações em periódicos e comunicações em anais de congressos e de seminários. [...], (FERREIRA, 2002, p. 258). 
Investigações com este caráter têm o intuito de agrupar os dados gerados por pesquisas, e assim promover novos apontamentos mediante as identificações realizadas. Assim, a pesquisa terá como locus de estudo os Anais dos principais encontros de Formação de professores e ensino de Ciências e Biologia.

O cenário no qual a pesquisa foi realizada corresponde aos, Encontro $\mathrm{Na}^{-}$ cional de Ensino de Biologia - (ENEBio); Encontro Nacional de Didática e Práticas de Ensino - (ENDIPE) e Encontro Nacional de Pesquisa em Ensino em Ciências - (ENPEC), no período de 2000 a 2016. Os Anais desses eventos foram consultados online através dos respectivos portais das entidades organizadoras.

Em seguida, realizou-se a leitura na íntegra dos sumários desses Anais, identificando através dos títulos de cada artigo, os estudos destinados à investigação de analogias em situações de aprendizagens. Quando não estava claro no título o objeto de estudo, foi realizada a leitura dos resumos das respectivas comunicações científicas.

\section{A pesquisa em analogias, o que mostram os Anais desses eventos}

$\mathrm{Na}$ busca por compreender o estado do conhecimento nas pesquisas em analogias no âmbito nacional, foi intuito dessa pesquisa quantificar as publicações referentes ao uso de analogias em contextos didáticos.

$\mathrm{Na}$ tabela 1 , pode ser observado o critério de organização do levantamento feito a partir da verificação nos Anais catalogados nesta pesquisa. Assim, podemos ver a distribuição das comunicações científicas segundo os Anais dos eventos inventariados. Para uma melhor compreensão, as comunicações identificadas nesta pesquisa foram contabilizadas e quantificadas segundo a natureza da publicação, conforme a legenda a seguir. R1-Resumo; R2-Resumo Expandido, A- Artigo completo, T- total.

Tabela 1 - Distribuição dos trabalhos segundo os anais do ENEBIO,ENDIPE e ENPEC, no período de 2000 a 2016.

\begin{tabular}{c|c|c|c|c|c|c|c|c|c|c|c|c|c|c}
\hline EVENTO & \multicolumn{3}{|c|}{ ENEBIO } & \multicolumn{4}{c|}{ ENDIPE } & \multicolumn{3}{c|}{ ENPEC } & & $T$ \\
\hline Tipo/escrita & $\mathrm{R}^{1}$ & $\mathrm{R}^{2}$ & $\mathrm{~A}$ & $T$ & $\mathrm{R}^{1}$ & $\mathrm{R}^{2}$ & $\mathrm{~A}$ & $T$ & $\mathrm{R}^{1}$ & $\mathrm{R}^{2}$ & $\mathrm{~A}$ & $T$ & \\
\hline No de trabalhos & - & 2 & 8 & 10 & 2 & 1 & 18 & 21 & 2 & 7 & 52 & 61 & 92 \\
\hline
\end{tabular}

Mediante coleta e diagnose desses Anais foram identificadas 92 comunicações científicas que trataram do emprego de analogias para fins de aprendizagem em diferentes áreas de conhecimento. Após a avaliação, esse material foi organizado em 6 linhas de pesquisa, onde duas delas ( V e VI) são contribuições novas em relação ao material já apresentado por Duarte (2005), conforme a tabela 2. 
Observou-se a predominância de investigações sobre a "Utilização e Exploração Didáticas de Analogias (linha I)" e as pesquisas sobre a presença de "Analogias em Manuais Escolares (linha II)" em detrimento das demais categorias (tabela 2).

Tabela - 2. Linhas de pesquisas diagnosticadas e a distribuição das publicações referentes à pesquisa sobre Analogias nas comunicações científicas presentes nos anais ENEBIO, ENDIPE e ENPEC no período de 2000 a 2016

\begin{tabular}{c|c|c|c|c}
\hline \multirow{2}{*}{ LINHAS $^{2}$} & \multicolumn{3}{|c|}{ EVENTOS } & \multirow{2}{*}{ TOTAL } \\
\cline { 2 - 5 } & ENEBIO & ENDIPE & ENPEC & \\
\hline I & 3 & 7 & 25 & 35 \\
\hline II & 1 & 7 & 19 & 27 \\
\hline III & 2 & 1 & 7 & 10 \\
\hline IV & 2 & 2 & 4 & 8 \\
\hline V & - & 1 & 3 & 4 \\
\hline VI & 2 & 4 & 6 & 12 \\
\hline
\end{tabular}

Para uma maior compreensão da relação estabelecida entre as linhas de pesquisa e as áreas de conhecimentos, mostramos no quadro 1, uma lista com algumas dessas investigações. O estabelecimento destas áreas de conhecimento trazem novos esclarecimentos acerca das inquietações que têm mobilizado as pesquisas no cenário nacional e apresenta um panorama geral dos caminhos percorridos nos estudos sobre analogia e a aprendizagem em Ciências. Compreender estes caminhos nos permite identificar, quais aspectos têm sido privilegiados, as contribuições do recurso didático aqui investigado, e suas limitações no contexto da aprendizagem.

Além das categorias apresentadas no estudo de Duarte (2005), a elaboração de novas categorias foi necessária para contemplar a diversidade de estudos identificados por meio deste inventário. Os estudos identificados que não se enquadram nas categorias inicialmente propostas revelam outras formas de análise para o objeto em estudo.

Quadro - 1. Representação dos componentes descritivos segundo a linha de pesquisa

\section{LINHA I - UTILIZAÇÃO E EXPLORAÇÃO DIDÁTICA DE ANALOGIAS}

SILVA, L. L.; GAZOLA, C. D.; TERRAZZAN, E. O uso de analogias no ensino de óptica: uma experiência em andamento. In. ENCONTRO NACIONAL DE PESQUISA EM EDUCAÇÃO EM CIÊNCIAS, 4., 2003, Bauru. Atas... Bauru, 2003.

BOZELLI, F. C.; NARDI, R. Explicação no ensino de física: ouso de analogias em sala de aula por licenciandos. In. ENCONTRO NACIONAL DE PESQUISA EM EDUCAÇẪO EM CIÊNCIAS, 6., 2007, Florianópolis. Atas... Florianópolis, 2007. 


\begin{tabular}{|c|}
\hline 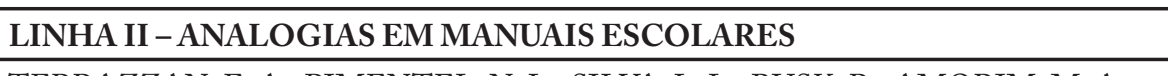 \\
\hline $\begin{array}{l}\text { ORIM, M. A. } \\
\text { biologia. In. } \\
\text { IENCIAS, } 5 . \text {, } \\
\text { tilização de } \\
\text { O NACIONAL } \\
\text { olis. Atas... }\end{array}$ \\
\hline \\
\hline $\begin{array}{l}\text { rofessores de biologia no ensino médio. In: ENCONTRO NACIONAL DE PESQUISA } \\
\text { M EDUCAÇÃO EM CIÊNCIAS, 3., 2001, A tibaia-SP. Atas... Atibaia - SP, } 2001 . \\
\text { LMEIDA, H. A.; LORENCINI JÚNIOR, A. O modelo TWA e os níveis de } \\
\text { granização das analogias: implicações para a prática docente. Revista da SBEnBio. n. 9, } \\
\text { 016. p. 55-67. }\end{array}$ \\
\hline \\
\hline $\begin{array}{l}\text { LIVEIRA, T. M. A.; MOZZER, N. B. Concepções de Futuros Professores de } \\
\text { uímica sobre Analogias: Uma análise das comparações elaboradas por licenciandos. In. } \\
\text { NCONTRO NACIONAL DE PESQUISA EM EDUCAÇÃO EM CIÊNCIAS, 10., } \\
\text { 15, Águas de Lindóia. Atas... Águas de Lindóia, 2015, p.1-8. } \\
\text { ANTANA, I. C. H.; SANTOS, F. A.; FEITOSA, E. M. A.É analogia! Você conhece? } \\
\text { chados de um minicurso sobre o tema para o ensino de ciências. Revista da SBEnBio. n. } \\
\text { 2016. p. 5458-5468. }\end{array}$ \\
\hline INHA V - ANALOGIAS E OS ESTUDOS DE REVISÃO \\
\hline HOFFMANN, M. B. DELIZOICOV, N. C.; MAESTRELLI, S \\
\hline LINH \\
\hline $\begin{array}{l}\text { ensino com } \\
\text { IONAL } \\
\text { Bauru, 2003. } \\
\text { evista } \\
\text { a07. }\end{array}$ \\
\hline
\end{tabular}


A partir do levantamento realizado observou-se que a temática analogia tem sido divulgada principalmente nos encontros de Ensino de Ciências, seguido dos encontros cuja temática central trata dos processos formativos e vivências pedagógicas.

Em um estudo realizado por Cruz-Hastenreiter (2015), que também buscou quantificar o número de publicações referentes ao estudo das analogias, em periódicos nacionais e internacionais de Ensino de Ciências no período de 1990 a 2012, foram identificadas 110 publicações.

Vale destacar que entre estes periódicos está incluso o número especial da revista Journal of Research in Science Teaching (JRST) publicado em 1993 para discutir a linguagem analógica e sua relação com a aprendizagem em Ciências e a Ciência.

Considerando o quantitativo identificado nos dois estudos, foi possível avultar que nos Anais pesquisados durante a realização dessa pesquisa - que se debruçaram sobre o intervalo de 16 (dezesseis) anos - apresentam um montante próximo dos identificados por Cruz-Hastenreiter (2015).

Entretanto, investigar apenas periódicos de divulgação científica deixa lacunas quanto à construção do estado da arte sobre o conhecimento do tema Analogia em Ensino de Ciências. Assim, compreende-se que o estudo desenvolvido complementa os dados disponíveis na literatura, e corrobora para a compreensão da temática.

A maior visibilidade das pesquisas sobre a categoria Utilização e exploração didática das analogias (linha I) foi também registrado por Duarte (2005). Pressupõese que os estudos cujos objetivos buscam compreender a funcionalidade da analogia nas práticas de ensino, decorram do entendimento de que este instrumento faz parte do exercício de ensino e aprendizagem.

No que concerne às pesquisas sobre o uso em livros didáticos tem despertado o interesse de muitos dos pesquisadores por reconhecer a centralidade que este recurso tem na dinâmica e execução das práticas de ensino.

A exploração da analogia na prática do professor e suas concepções sobre este instrumento foi registrado em um menor número de pesquisas. No entanto, é notória a importância de compreender a relação estabelecida entre o professor e esse recurso.

\section{Terminologias associadas à analogia}

Em meio à diversidade de trabalhos e dos teóricos que fundamentam diferentes produções bibliográficas analisadas neste estudo, uma variedade de terminologias foram observadas, assim como, na pesquisa de Duarte (2005).

As variações terminológicas foram identificadas na denominação dos domínios de conhecimento familiar e não familiar. $\mathrm{Na}$ literatura nacional pesquisada neste estudo, observou-se que há um desacordo entre os pesquisadores quanto ao emprego de uma denominação única nas pesquisas para referir-se ao domínio conhecido, familiar, a exemplo de denominações como Análogo (FERRAZ; TERRAZAN, 2001; 
ALMEIDA; LORENCINI JUNIOR, 2016); Veículo (NAGEM; SOUZA, 2012; DINIZ; SANTOS, 2013); Foro (RIVELLI; LEMGRUBER, 2012); Fonte (QUEIROZ; GUIMARÃES; BOA, 2001; BOZELLI; NARDI, 2005); Base (FERRY; PAULA, 2015; CUNHA; JUSTI, 2007).

No que se refere à denominação do domínio desconhecido ou não familiar, a terminologia Alvo predomina a exemplo dos trabalhos de (CUNHA, 2007; PEDROSO, 2008), ou Tema (RIVELLI; LEMGRUBER, 2012).

Apesar do pluralismo evidenciado nas denominações empregadas para referir-se ao domínio de conhecimento familiar ao educando, as terminologias utilizadas se encontram em consonância com as descrições feitas por Duarte (2005).

Deste ponto de vista, observa-se haver um alinhamento entre o escopo teórico nacional e o internacional apresentado pela autora.

É bastante coesa a literatura que trata do emprego dos termos utilizados para referir-se ao domínio de conhecimento desconhecido da relação analógica. Assim, o corpo teórico que se constitui no âmbito nacional apresenta-se mais coerente quando comparado ao cenário internacional.

\section{Contribuições e limitações associadas ao uso de analogias}

Diferentes modos de avaliação para o uso de analogias como elemento facilitador do processo de aprendizagem e instrumento de mediação na prática de professores foram registrados, bem como, algumas concepções desse uso que tendem a favorecer o emprego deste recurso no exercício da docência e, em matérias que falam sobre Ciência.

De modo geral, podem ser destacadas algumas concepções, associadas às contribuições quanto ao uso da analogia, são elas: uma melhor compreensão de conceitos abstratos; possibilitando a mudança conceitual; a promoção do desenvolvimento de competências cognitivas, tais como, percepção, imaginação, criatividade, memória e resolução de problemas; podendo ser utilizada como instrumento de avaliação; como ferramenta interativa, discursiva e reflexiva na relação professor-aluno e aluno-aluno; estimulando para o raciocínio analógico e para uma visão holística da Ciência.

Embora se observe as muitas possibilidades de uso e suas contribuições, às limitações relacionadas ao emprego de analogias no processo de ensino pode ser observado, mesmo que em um menor número de contraindicações, destacando: Formação de obstáculos epistemológicos, em situações nas quais as analogias substituem ou desviam o conteúdo ensinado; dessa forma, ela pode ser interpretada como o conceito em análise, no qual não há uma distinção clara entre a analogia e próprio conceito; ou seja, reforça ideias equivocadas ou fica apenas com as características do análogo por não haver um ajuste exato entre o alvo e o análogo.

Encontra-se a seguir, no quadro 2, um resumo geral dos dados identificados neste estudo permitindo verificar a distribuição das linhas de pesquisa elabora- 
das segundo área de conhecimento, níveis de ensino, métodos e técnicas empregados, vantagens e desvantagens quanto ao uso da analogia para o processo de transposição didática.

Quadro 2 - Quadro descritivo dos principais resultados encontrados na análise de estudos sobre analogias nos anais dos encontros ENEBIO, ENDIPE e ENPEC entre 2000 a 2016

\begin{tabular}{|c|c|c|c|c|c|}
\hline Linhas & Área & $\begin{array}{c}\text { Níveis de } \\
\text { ensino }\end{array}$ & Metodologia & Vantagens & Dificuldades \\
\hline 1 & $\begin{array}{l}\text { Ciências, } \\
\text { Biologia, } \\
\text { Química, } \\
\text { Física, } \\
\text { Metod. } \\
\text { Científica, } \\
\text { Robótica, } \\
\text { Música, } \\
\text { Ed. Sexual. }\end{array}$ & $\begin{array}{l}\text { Fundamental, } \\
\text { Médio, EJA, } \\
\text { Superior. }\end{array}$ & $\begin{array}{l}\text { Estudo } \\
\text { de Caso, } \\
\text { Método } \\
\text { clínico, } \\
\text { Estudos } \\
\text { etnográficos. }\end{array}$ & $\begin{array}{l}\text { Aprendizagem, } \\
\text { Concentração, } \\
\text { Raciocínio, } \\
\text { Participação } \\
\text { ativa. }\end{array}$ & $\begin{array}{l}\text { Estabelecer } \\
\text { relações entre } \\
\text { alvo/ análogo; } \\
\text { Identificar } \\
\text { limites e } \\
\text { validades da } \\
\text { analogia; } \\
\text { Compreender } \\
\text { o processo } \\
\text { em nível } \\
\text { microscópico }\end{array}$ \\
\hline 2 & $\begin{array}{l}\text { Ciências, } \\
\text { Biologia, } \\
\text { Química, } \\
\text { Física, } \\
\text { Matemática, } \\
\text { Fisioterapia. }\end{array}$ & $\begin{array}{l}\text { Fundamental, } \\
\text { Médio, } \\
\text { Superior }\end{array}$ & $\begin{array}{l}\text { Classificação } \\
\text { de Glynn } \\
(1991) \\
\text { TWA } \\
\text { modificado, } \\
\text { Harrison } \\
\text { eTreagust } \\
\text { (1994), } \\
\text { Curtins e } \\
\text { Reigelututh } \\
\text { (1984), } \\
\text { Queiroz } \\
\text { (2000), } \\
\text { Ferraz e } \\
\text { Terrazzan } \\
\text { (2001). }\end{array}$ & $\begin{array}{l}\text { Facilita a } \\
\text { apresentação } \\
\text { de conceitos; } \\
\text { Mudança } \\
\text { conceitual }\end{array}$ & $\begin{array}{l}\text { Promovem a } \\
\text { hominização dos } \\
\text { conceitos; } \\
\text { A maioria das } \\
\text { analogias não } \\
\text { contempla a } \\
\text { metodologia } \\
\text { TWA; } \\
\text { Apresentação } \\
\text { analógica na } \\
\text { forma verbal; }\end{array}$ \\
\hline 3 & $\begin{array}{l}\text { Biologia, } \\
\text { Química, } \\
\text { Física, } \\
\text { Balé. }\end{array}$ & $\begin{array}{l}\text { Fundamental, } \\
\text { Médio, } \\
\text { Superior. }\end{array}$ & $\begin{array}{l}\text { Estudos } \\
\text { etnográficos, } \\
\text { Estudos de } \\
\text { caso }\end{array}$ & $\begin{array}{l}\text { Transposição } \\
\text { de temas } \\
\text { conceituais; } \\
\text { Colabora } \\
\text { para falar de } \\
\text { Ciência; } \\
\text { Fortalece a } \\
\text { comunicação } \\
\text { professor- } \\
\text { aluno. }\end{array}$ & $\begin{array}{l}\text { Desconhecimen- } \\
\text { to de metodolo- } \\
\text { gias próprias; } \\
\text { Não estabelecem } \\
\text { correspondên- } \\
\text { cias entre alvo/ } \\
\text { análogo; }\end{array}$ \\
\hline
\end{tabular}


Continuação do Quadro 2

\begin{tabular}{|c|c|c|c|c|c|}
\hline 4 & $\begin{array}{l}\text { Ciências da } \\
\text { Natureza, } \\
\text { Química, } \\
\text { Biologia }\end{array}$ & $\begin{array}{l}\text { Fundamental, } \\
\text { Médio, } \\
\text { Superior }\end{array}$ & $\begin{array}{l}\text { Estudo de } \\
\text { caso }\end{array}$ & $\begin{array}{l}\text { Facilitam a } \\
\text { compreensão } \\
\text { de temas } \\
\text { abstratos, } \\
\text { Tornam os } \\
\text { conceitos mais } \\
\text { inteligíveis, } \\
\text { Ativa o } \\
\text { raciocínio } \\
\text { analógico e } \\
\text { argumentação. }\end{array}$ & $\begin{array}{l}\text { Desconheci- } \\
\text { mento sobre a } \\
\text { temática; } \\
\text { Confusão sobre } \\
\text { o que deno- } \\
\text { minam como } \\
\text { analogias; }\end{array}$ \\
\hline 5 & $\begin{array}{l}\text { Ensino de } \\
\text { Ciências, } \\
\text { Biologia }\end{array}$ & - & $\begin{array}{l}\text { Revisão } \\
\text { bibliográfica }\end{array}$ & $\begin{array}{l}\text { Diagnóstico } \\
\text { do estado da } \\
\text { questão; }\end{array}$ & $\begin{array}{l}\text { Estudos na área } \\
\text { incipientes }\end{array}$ \\
\hline 6 & $\begin{array}{l}\text { Ciências, } \\
\text { Divulgação } \\
\text { em Ciências, } \\
\text { Física, } \\
\text { Pedagogia }\end{array}$ & $\begin{array}{l}\text { Fundamental, } \\
\text { Médio, } \\
\text { Superior }\end{array}$ & $\begin{array}{l}\text { Ensaio } \\
\text { teórico, } \\
\text { Análise de } \\
\text { livro, } \\
\text { TWA } \\
\text { modificado } \\
\text { por Harisson } \\
\text { e Triagust } \\
\text { (1994), } \\
\text { MECA }\end{array}$ & $\begin{array}{l}\text { Facilita a } \\
\text { aprendizagem, } \\
\text { Analogias } \\
\text { associadas } \\
\text { a imagens } \\
\text { facilitam a } \\
\text { compreensão }\end{array}$ & $\begin{array}{l}\text { Metáforas/ } \\
\text { analogias } \\
\text { empregadas } \\
\text { em contextos } \\
\text { didáticos } \\
\text { podem ser } \\
\text { compreendidas } \\
\text { em sentido } \\
\text { literal. }\end{array}$ \\
\hline
\end{tabular}

Fonte: Elaborado pelos autores.

Considerando o diagnóstico realizado, observou-se que o reconhecimento e avaliação do uso de analogias em situações de aprendizagem distribuem-se sobre as diferentes áreas de conhecimento e níveis de ensino. Tal fato, sugere sua ampla utilização nas rotinas de aprendizagem, consequentemente desperta o interesse pelo objeto de estudo e constitui sua relevância para cenário educacional. Em razão da pluralidade dos sujeitos e dos objetos de estudo que varia entre as pesquisa, os métodos e técnicas também são diversos para abarcar o universo de dados levantados, e assim, ampliar as possibilidades de discussão.

Quanto aos resultados descritos, a literatura demonstra-se assertiva ao uso de analogias como ferramenta de transposição didática, pois, possibilita diferentes mobilizações de capacidades necessárias ao ensino. Mas, é consenso entre os pesquisadores que tais proposições devem estar associadas a um uso planejado e sistemático. 


\section{Conclusões}

Com esse estudo foi possível constatar a relevância do tema no meio das pesquisas educacionais que investigam o Ensino de Ciências. Sobre este aspecto, diferentes áreas disciplinares têm buscado compreender a relação deste instrumento com as práticas de ensino e com o processo formativo. Embora, considerando a distribuição geográfica da origem e da vinculação dos pesquisadores que estudam sobre analogias, há uma diversidade de denominações das terminologias aplicadas para nomear os domínios de conhecimentos familiares e desconhecido, assim como diagnosticado em outros estudos. Contudo, no que concerne o entendimento da representatividade da analogia e de sua definição, a literatura nacional encontra-se claramente estabelecida não havendo entre os pesquisadores equívocos sobre a sua compreensão.

Percebeu-se que o emprego de analogias tem sido alinhado por diferentes autores, com as concepções de ensino construtivistas e com o processo de aprendizagem significativa. Ou seja, são perspectivas de ensino que expressam o uso de analogias com finalidades pedagógicas que favorecem um processo formativo ao aluno dandolhe maior autonomia, conhecimento e criticidade não apenas sobre os conteúdos em si, mas, acerca do processo de ensino como um todo.

$\mathrm{Na}$ análise das diferentes categorias estabelecidas nesta investigação, verificou-se que os estudos voltados ao Ensino de Física foram os mais abordados na maioria das pesquisas, seguidos de estudos na área de Química e Biologia. A centralidade do uso do referido recurso decorrer da abordagem direta de temas e conceitos abstratos, sendo então exploradas nos discursos e materiais empregados para comunicar sobre Ciências, seus conceitos, metodologias e resultados. O incremento desta forma de tratar o conhecimento científico representa uma forma inovadora nas práticas de ensino.

Apesar da utilização da linguagem analógica como instrumento mediador da aprendizagem conceitual, seu emprego tem estado associado ao desenvolvimento de outras capacidades, tais como, argumentativa, resolução de problemas, criatividade na tomada de decisão, criticidade e reflexão sobre o processo de aprendizagem. Ao evocar tais competências no processo de aprendizagem do educando, o perfil formativo do sujeito é ampliado possibilitando novas formas de relacionar-se com os conteúdos científicos e sua relação com seu espaço.

Ainda que essas contribuições sejam conferidas ao processo de ensino, alguns apontamentos têm sido feitos no sentido contrário ao da aprendizagem. Entre os contrapontos ao uso da analogia na aprendizagem em Ciências, está o desenvolvimento de concepções alternativas, ao considerar que o raciocínio analógico não ocorre, ou que fiquem apenas os elementos apelativos das comparações. O estabelecimento destas limitações é considerado como limitante ao processo de ensino.

De modo geral, as produções analisadas apresentam algumas limitações, a principal delas, o desrespeito à estruturação de seus resumos que não fazem sentido completo e nem descrevem com precisão o processo metodológico, o que dispensa a leitura integral dos estudos em certos casos. Nessa etapa das comunicações científicas, em muitos trabalhos, há ausência de descrições sobre resultados e conclusões, obtidos nos estudos. 
Assim, entende-se que as pesquisas na área têm impactado de forma tênue nos processos formativos, e na elaboração e uso de analogias na promoção do Ensino de Ciências, requerendo então, ações que propiciem a discussão e reconhecimento deste instrumento de forma clara e direta com os fenômenos da aprendizagem.

\section{Referências}

ALMEIDA, Hederson Aparecido; LORENCINI JÚNIOR, Álvaro. Analogias e metáforas: um panorama da produção acadêmica da área de Ensino de Ciências. In. ENCONTRO NACIONAL DE PESQUISA EM EDUCAÇÃO EM CIÊNCIAS, 10, 2015, Águas de Lindóia. Atas... Águas de Lindóia, 2015, p.1-8.

ANDRÉ, Marli. Pesquisa em educação: buscando rigor e qualidade. Cadernos de Pesquisa. [online]. 2001, n.113, p.51-64. ISSN 0100-1574. Disponível em:< http://dx.doi.org/10.1590/ S0100-15742001000200003 >. Acesso em: 02 de jun. 2017.

BIZZO, Nélio. Mais ciência no ensino fundamental: metodologia de ensino em foco. São Paulo: Editora do Brasil, 2009.144p.

BOZELLI, Fernanda Catia; NARDI, Roberto. O uso de analogias e metáforas em aulas de física no ensino superior: algumas considerações. In. ENCONTRO NACIONAL DE PESQUISA EM EDUCAÇÃO EM CIÊNCIAŞ, 5., 2005, Bauru. Atas... Bauru, 2005.

BOZELLI, Fernanda Catia; NARDI, Roberto. O uso de analogias e os processos interativos discursivos: possíveis relações. In. ENCONTRO NACIONAL DE PESQUISA EM EDUCAÇÃO EM CIÊNCIAS, 7., 2009, Florianópolis. Atas... Florianópolis, 2009.

CRUZ-HASTENREITER, Roberto Soares da. Das palavras aos quanta: analogias em aulas de física quântica. In. ENCONTRO NACIONAL DE PESQUISA EM EDUCAÇÃO EM CIÊNCIAS, 10., 2015, Águas de Lindóia. Atas... Águas de Lindóia, 2015, p. 1-8.

CUNHA, Mariana de Carvalho Capistrano. A compreensão de analogias por crianças das primeiras séries do ensino fundamental. In: ENCONTRO NACIONAL DE ENSINO DE BIOLOGIA, 2., 2007. Cidade. Anais... Uberlândia: Sociedade Brasileira de Ensino de Biologia, 2007.

CUNHA, Mariana de Carvalho Capistrano; JUSTI, Rosária da Silva. Analogias sobre nutrição e digestão elaboradas por crianças do ensino fundamental. In. ENCONTRO NACIONAL DE PESQUISA EM EDUCAÇÃO EM CIÊNCIAS, 6., 2007, Florianópolis. Atas... Florianópolis, 2007.

CURTIS, Ruth.; REIGELUTH, Charles. The Use of Analogies in Written Text. Instructional Science, v. 13, p. 99-117, 1984

DAGHER, Zoubeida.. Review of studies on the effectiveness of instructional analogies in Science Education. Science Education. v. 79, n. 3, p. 295-312, jun. 1995.

DINIZ, Rafael Henriques Nogueira; SANTOS, Míriam Stassun dos. O Pensamento Analógico como instrumento de aprendizagem: o uso de analogias na robótica educacional. In. ENCONTRO NACIONAL DE PESQUISA EM EDUCAÇÃO EM CIÊNCIAS, 9., 2013, Águas de Lindóia, SP. Atas... Águas de Lindóia, 2013, p.1-8.

DUARTE, Maria da Conceição. Analogias na educação em ciências: contributos e desafios. Investigações em Ensino de Ciências. v.10, n.1, p.7-29. Disponível:<http://www.if.ufrgs.br/ public/ensino/revista.htm. . . Acesso em 18 fev. 2016.

FERRAZ, Daniela Frigo; TERRAZZAN, Eduardo Adolfo. O uso de analogias como recurso didático por professores de Biologia no Ensino Médio. Revista da ABRAPEC. Belo Horizonte: UFMG. v.1, n.3, p.124-135. 2001. 
FERREIRA, Norma Sandra de Almeida. As pesquisas denominadas "estado da arte". Educação e Sociedade [online]. 2002, v.23, n.79, p.257-272. ISSN 0101-7330. Disponível em:<http://dx.doi. org/10.1590/S0101-73302002000300013 . Acesso em 25 mar. 2017.

FERRY, Alexandre da Silva; PAULA, Helder de Figueirêdo e. Mapeamento estrutural de analogias e outras comparações em uma sala de aula de Química. In. ENCONTRO NACIONAL DE PESQUISA EM EDUCAÇÃO EM CIÊNCIASS, 10., 2015, Águas de Lindóia. Atas... Águas de Lindóia, 2015, p.1-8.

GIL. Antônio Carlos. Como elaborar projetos de pesquisa. 4. ed. São Paulo: Atlas, 2002. 192p.

GLYNN, Shawn. M. Explaing science concepts: a teaching-with-analogies model. In: GLYNN, Shawn M.; YEANY, Russell H.; BRITTON, Bruce K. The psychology of learning science. New Jersey: Lawrence Erlbaum Associate, p. 219-240, 1991.

HARRISON, Allan G; TREAGUST, David F. Teaching with Analogies: A Case Study in Grade-10 Optics. Journal of Research in Science Teaching, v. 30, n.10, p.1291-1307, 1993.

LAKATOS, Eva Maria; MARCONI, Marina de Andrade. Fundamentos de metodologia científica. 5. ed. São Paulo: Atlas, 2003. 320p.

MEGID NETO, Jorge; PACHECO, Décio. Pesquisas sobre o ensino de física no Brasil: concepções e tratamentos de problemas em teses e dissertações. In: NARDI, R. (Org.). Pesquisas em ensino de física. 1ed. São Paulo: Escrituras, 1998.

MOZZER, Nilmara Braga; JUSTI, Rosária. "Nem tudo que reluz é ouro”: Uma discussão sobre analogias e outras similaridades e recursos utilizados no ensino de Ciências. Revista Brasileira de Pesquisa em Educação em Ciências. v. 15, n.1, p. 123-147. 2015.

NAGEM, Ronaldo Luiz; SOUZA, João Rodolfo Lauton Miranda de. Identificação de analogias em livros de Fisioterapia. In. ENCONTRO NACIONAL DE PESQUISA EM EDUCAÇÃO EM CIÊNCIAS, 8., 2011. Campinas, Atas... Campinas, 2011, p. 1-11.

PEDROSO, Cristiane. As apresentações analógicas em vídeos de divulgação científica. In: ENCONTRO NACIONAL DE DIDÁTICA E PRÁTICA DE ENSINO, 14., 2008, Porto Alegre. Anais... Porto Alegre, 2008.

QUEIROZ, Glória Regina Pessôa Campello. Professor artista-reflexivos de física no ensino médio. Tese (Doutorado em Educação) - Programa de Pós-Graduação em Educação, Pontifícia Universidade Católica do Rio de Janeiro. 2000. 350 f.

QUEIROZ, Glória; GUIMARÃES, Luiz Alberto; BOA, Marcelo Cordeiro Fonte. O professor artista-reflexivo de física, a pesquisa em ensino de física e a modelagem analógica. In. ENCONTRO NACIONAL DE PESQUISA EM EDUCAÇÃO EM CIÊNCIAS, 3., 2001, Atibaia - SP. Atas... Atibaia - SP ADE, 2001.

RIVELLI, Helena; LEMGRUBER, Márcio Silveira. Namoro atômico: um estudo de caso sobre a analogia do relacionamento. In: ENCONTRO NACIONAL DE ENSINO DE BIOLOGIA, 4., 2012. Goiânia. Anais.... Goiânia: Sociedade Brasileira de Ensino de Biologia, 2012.

SILVA, Leandro Londero da; TERRAZZAN, Eduardo Adolfo. As analogias no ensino de conteúdos conceituais de física. In. ENCONTRO NACIONAL DE PESQUISA EM EDUCAÇÃO EM CIÊNCIAS, 5., 2005, Bauru. Atas... Bauru, 2005b.

TEIXEIRA, Paulo Marcelo Marini; MEGID NETO, Jorge. Investigando a pesquisa educacional: um estudo enfocando dissertações e teses sobre o ensino de biologia no Brasil. Investigações em Ensino de Ciências. v.11, n.2, p. 261-282, 2006. 


\section{Notas}

1 Esta pesquisa é um tributo ao Trabalho de Conclusão de Curso (TCC), apresentado pelo primeiro autor.

2 As linhas foram denominadas em: linha I: utilização e exploração didática de analogias, linha II: as analogias em manuais escolares; linha III as analogias na prática dos professores de ciências; linha IV: as analogias e as concepções de professores sobre o seu papel no processo de ensino-aprendizagem; linha $\mathrm{V}$ : analogias e os estudos de revisão; linha VI: analogias e ensino. T: total por evento.

* Licenciado em Ciências Biológicas pela Faculdade de Educação de Itapipoca FACEDI/Universidade Estadual do Ceará, Fortaleza, Ceará, Brasil.

** Professora Adjunta de Prática de Ensino em Biologia da Faculdade de Educação de Itapipoca FACEDI/ Universidade Estadual do Ceará, Fortaleza, Ceará, Brasil.

\section{Correspondência}

Francisco Alves Santos - Universidade Estadual do Ceará. Av. Dr. Silas Munguba, 1700 Campus do Itaperi. CEP: 60741-000. Fortaleza, Ceará, Brasil.

E-mail: fabier.santos@aluno.uece.br - isabel.higino@uece.br

Recebido em 28 de abril de 2018

Aprovado em 18 de julho de 2018

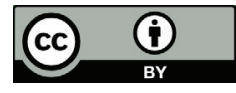

This work is licensed under a Creative Commons Attribution 4.0 International (CC BY 4.0). 